\title{
Initial bronchoscopic treatment for patients with intraluminal bronchial carcinoids
}

Hes A. P. Brokx, MD, ${ }^{a}$ Elle K. Risse, MD, PhD, ${ }^{b}$ Marinus A. Paul, MD, PhD, ${ }^{c}$ Katrien Grünberg, MD, PhD, ${ }^{b}$ Richard P. Golding, MD, ${ }^{d}$ Peter W. A. Kunst, MD, PhD, ${ }^{a}$ Jan-Peter Eerenberg, MD, PhD, ${ }^{c}$ Johan C. van Mourik, MD, ${ }^{c}$ Pieter E. Postmus, MD, PhD, ${ }^{\text {a }}$ Wolter J. Mooi, MD, PhD, and Tom G. Sutedja, MD, PhD ${ }^{\mathrm{a}}$

Objective: Carcinoid of the lung is considered low-grade malignancy, and less invasive treatment may therefore be considered. We analyzed the long-term outcome of initial bronchoscopic treatment in patients with intraluminal bronchial carcinoids.

Methods: Initial bronchoscopic treatment was applied to improve presurgical condition, to obtain tissue samples for proper histologic classification, and to enable less extensive parenchymal resection. For intraluminal bronchial carcinoid, complete tumor eradication with initial bronchoscopic treatment was attempted. High-resolution computed tomography in addition to bronchoscopy was used to determine intraluminal versus extraluminal tumor growth. Surgery followed in cases of atypical carcinoid, residue, or recurrence.

Results: Seventy-two patients, 43 of them female, have been treated (median age 47 years, range 16-80 years). Median follow-up has been 65 months (range 2-180 months). Fifty-seven (79\%) had typical carcinoids and $15(21 \%)$ had atypical carcinoids. Initial bronchoscopic treatment resulted in complete tumor eradication in 33 of 72 cases (46\%), 30 typical and 3 atypical. Thirty-seven of 72 cases (51\%), 11 atypical, required surgery ( 2 for late detected recurrences). Two patients had metastatic atypical carcinoid, 1 already at referral. Of the 6 deaths, 1 was tumor related.

Conclusions: Initial bronchoscopic treatment is a potentially more tissue-sparing alternative than immediate surgical resection in patients with intraluminal bronchial carcinoids. For successful tumor eradication with initial bronchoscopic treatment in central carcinoids, assessment of intraluminal versus extraluminal growth may be of much more importance than histologic division between typical and atypical carcinoid. Disease-specific mortality is low, and long-term outcome has been excellent. Implementation of initial bronchoscopic treatment had no negative impact on surgical treatment outcome.

From the Departments of Pulmonary Diseases, ${ }^{\mathrm{a}}$ Pathology, ${ }^{\mathrm{b}}$ Surgery, ${ }^{\mathrm{c}}$ and Radiology, ${ }^{\mathrm{d}}$ VU University Medical Center, Amsterdam, The Netherlands.

Received for publication Aug 30, 2006; revisions received Dec 1, 2006; accepted for publication Dec 12, 2006.

Address for reprints: T. G. Sutedja, MD, $\mathrm{PhD}$, Department of Pulmonary Diseases, VU University Medical Center, PO Box 7057, 1007 MB Amsterdam, The Netherlands (E-mail: tg.sutedja@vumc.nl).

J Thorac Cardiovasc Surg 2007;133:973-8

$0022-5223 / \$ 32.00$

Copyright $\odot 2007$ by The American Association for Thoracic Surgery

doi:10.1016/j.jtcvs.2006.12.013

$\mathrm{B}$ ronchial carcinoid (BC) tumors, members of the neuroendocrine group of tumors, comprise $2 \%$ to $5 \%$ of all primary lung tumors. ${ }^{1,2}$ Carcinoids are classified as either typical carcinoid (TC) or atypical carcinoid (AC) according to the classification criteria of Travis and colleagues, ${ }^{3}$ which are based on retrospective analyses of specimens from surgical series. The fact that AC tends to show more lymphatic and metastatic spread than does $\mathrm{TC}^{2,4-7}$ and the possibility of submucosal and extraluminal tumor growth seem overwhelmingly to warrant immediate surgery as the only acceptable alternative. ${ }^{2,8-11}$

Current knowledge of tumor biology and growth pattern and increased use of minimally invasive techniques, however, have improved our understanding and evaluation of disease processes, enabling a more tailored approach for each indi- 


\author{
Abbreviations and Acronyms \\ $\mathrm{AC}=$ atypical carcinoid \\ $\mathrm{BC}=$ bronchial carcinoid \\ HRCT $=$ high-resolution computed tomography \\ IBT = initial bronchoscopic treatment \\ $\mathrm{TC}=$ typical carcinoid
}

vidual at risk and allowing tissue-sparing alternatives to surgical intervention. ${ }^{6,12-14}$ Such a consideration within various oncology disciplines may allow optimal preservation of quality of life without compromising outcome. ${ }^{15}$ Both improved knowledge and technical innovations should lead to critical review of conclusions that were based on previous clinical data regarding BC. Compared with AC, TC has excellent 5- and 10-year survivals of $87 \%$ to $100 \%$ and $82 \%$ to $87 \%$, respectively, versus $56 \%$ to $75 \%$ and $25 \%$ to $59 \%$, respectively. Even in cases with positive lymph nodes, TC and, to a lesser extent, AC still have acceptable survivals: for TC, 5-year survivals as great as $100 \%$, and for AC, 5 -year survivals of $25 \%$ to $78 \%$ and 10 -year survivals of $25 \%$ to $59 \%$., $3,8-11,16$ These survival data are based on surgically resected specimens without detailed information of bronchoscopic findings.

On the basis of and encouraged by our previous experiences ${ }^{17-19}$ regarding initial bronchoscopic treatment (IBT) for central airway tumors before surgical resection, we report here the long-term outcome of our strategy regarding BC.

\section{Patients and Methods}

Patients first seen with BC in the central airway (wholly or partially intraluminal BCs) in the period 1991 to 2005 were prospectively entered in this study protocol after informed consent. At that time, the regulatory requirement from the scientific committee was oral informed consent after full information about the pros and cons of IBT strategy. Patients and family members were fully informed, especially about potential disadvantages of IBT relative to the standard treatment, surgical resection. Our IBT strategy, which is based on best clinical practice, is shown in Figure 1. In conjunction with improvements in diagnostic and therapeutic modalities, our strategy has also been evolving to current use of state-of-the-art technologies.

All patients referred to our institution underwent IBT with propofol anesthesia, with both rigid and flexible bronchoscopes used to obtain the maximum amount of tissue for proper histologic diagnosis, to improve patient condition in case of obstructive pneumonia, and to enable less extensive resection whenever feasible. Clearance of the tumor was mostly performed by mechanical removal and application of Nd:YAG laser or electrocautery. ${ }^{20}$ Within 6 weeks after IBT, high-resolution computed tomography (HRCT) was

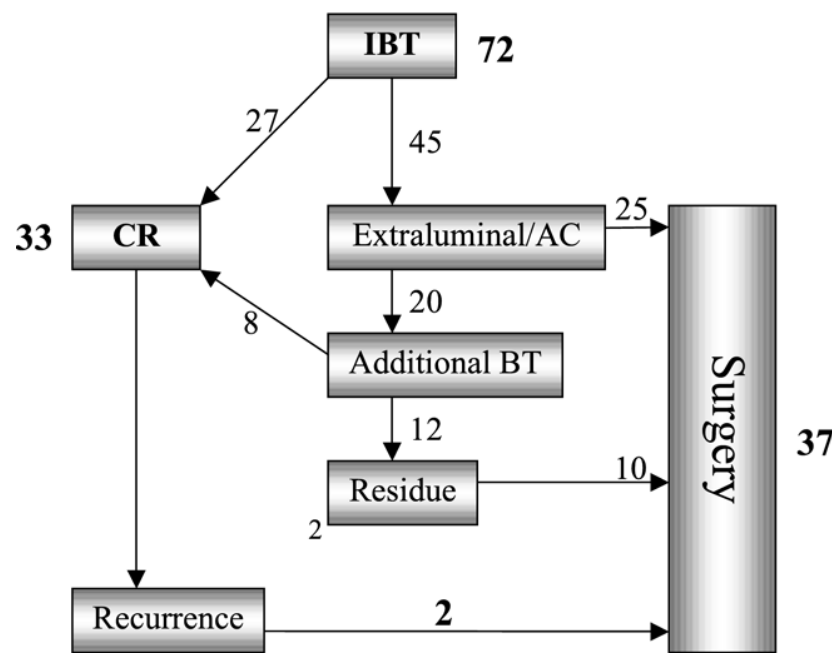

Figure 1. Initial bronchoscopic treatment (IBT) strategy in bronchial carcinoids. $C R$, complete response with no residual tumor detected macroscopically (videobronchoscopy, high-resolution computed tomography, and endobronchial ultrasonography since 2003) and microscopically (biopsy and brush specimens); $A C$ atypical carcinoid; $B T$, bronchoscopic treatment. Extraluminal extension assessed with high-resolution computed tomography. Numbers of patients in each arm of our strategy are also shown.

performed to determine intraluminal versus extraluminal tumor growth, with flexible bronchoscopy repeated to evaluate the IBT result. Because BC may be seen with postobstructive pneumonia, a clear distinction between intraluminal and extraluminal extension can only be properly made once postobstructive debris and atelectasis have been cleared. In cases of obvious extraluminal disease, atypical histologic type, unsuccessful intraluminal treatment, or recurrence, surgical resection was performed for radical tumor removal with complete mediastinal lymph node dissection. IBT was considered successful when there was no sign of residual disease (by videobronchoscopy, biopsy, thin-slice HRCT images, and radial endobronchial ultrasonography). Repeated evaluation was then performed semiannually in the first 2 years and annually up to 5 years. Beyond the fifth year, patients have been referred back to their pulmonologists for further yearly check-ups.

Some patients, treated before the introduction of HRCT, have been monitored with more traditional computed tomography with slice thickness of $5 \mathrm{~mm}$. Currently, with 64-multidetector computed tomography, slice thickness is $0.75 \mathrm{~mm}$ with $0.5-\mathrm{mm}$ overlap, with additional viewing possibilities of multiplanar reconstruction and virtual bronchoscopy as well. Recent use of endobronchial ultrasonography with a $20-\mathrm{MHz}$ radial transducer enables us to detect minute bronchial wall abnormalities on the submillimeter order. $^{21}$ 
TABLE 1. Patients with bronchial carcinoid of the central airways: Characteristics and symptoms at referral

\begin{tabular}{lcc}
\hline & $\begin{array}{c}\text { Typical } \\
\text { carcinoid }\end{array}$ & $\begin{array}{c}\text { Atypical } \\
\text { carcinoid }\end{array}$ \\
\hline No. of patients & 57 & 15 \\
Sex (No.) & 26 & 3 \\
$\quad$ Male & 31 & 12 \\
$\quad$ Female & $47(17-77)$ & 44 (16-80) \\
Age (y, median and range) & & \\
Smoking status (No.) & 24 & 7 \\
$\quad$ Nonsmoker & 24 & 7 \\
Former smoker & 9 & 1 \\
$\quad$ Current smoker & & \\
Presenting symptoms (No.) & 17 & 8 \\
Pneumonia & 14 & 1 \\
$\quad$ Hemoptysis & 1 & 0 \\
Both pneumonia and hemoptysis & 11 & 5 \\
Dyspnea & 6 & 1 \\
Persistent cough & 8 & 0 \\
$\quad$ Other & & \\
\hline
\end{tabular}

The definitive histologic diagnosis (TC vs AC) was based on the maximum amount of tissue ultimately sampled. All samples collected before 1998 were reclassified according to the Travis classification. ${ }^{3}$ Surgery was always with systematic nodal dissection, and the least extensive parenchymal resection had always been attempted. ${ }^{6,12}$

We also analyzed the number of patients from the archives of the Dutch Central Tumor Registry to compare the number of individuals registered with BC in the Netherlands during the same study period.

\section{Results}

Seventy-two patients have been treated, with a median follow up as of August 2006 of 65 months (range 2-180 months). Patient characteristics and symptoms at referral are shown in Table 1. Relative to the total number of individuals with $\mathrm{BC}$ in the Netherlands in the registry crude data, this study represents about $10 \%$ of the total BCs diagnosed during the entire study period.

Results of our bronchoscopic treatment strategy are shown in Table 2 and Figure 1. After $1(n=27), 2(n=7)$, or $4(n=$ 1) IBT sessions, 35 patients had complete tumor eradication and were subjected to long-term follow-up. Of the remaining 37 patients, 35 underwent completion surgery; all were N0 status. We performed 12 lobectomies, 6 sleeve lobectomies, 10 bilobectomies, 1 sleeve bilobectomy, and 6 pneumonectomies. In 2 cases, less extensive resections were enabled by IBT. One patient, with postoperatively proven extraluminal extension, required emergency surgical resection for persistent hemorrhage during IBT. In 30 cases, involvement of the bronchial wall or extension into the parenchyma was found, rendering surgical resection necessary.

In 2 cases, complete tumor eradication by IBT was not achieved: 1 patient refused surgery and is alive (follow-up 110 months); the other had metastatic disease at referral, was therefore treated in a palliative setting, and is still alive (follow-up 27 months). Both are currently well without pulmonary symptoms.

Two patients for whom yearly follow-up was stopped after the fifth year had late detected recurrences and underwent surgical resection at 103.5 and 115.5 months after IBT. These patients were therefore eventually placed in the surgical group.

Currently, 33 patients still have complete remission after IBT (median follow-up 72.5 months, range 2-180 months). IBT in 3 patients obtained complete remission of what was proven to be $\mathrm{AC}\left(4,5\right.$, and 7 mitoses $\left./ 2 \mathrm{~mm}^{2}\right)$. Because evaluation did not show any residual disease, completion surgery has so far been postponed. Follow-up has been 14 to 74.5 months. Follow-up figures for the different cohorts are shown in Table 3A.

Six patients $(6 / 72,8 \%)$ have died. Four had TC and 1 had $\mathrm{AC}$, with all dying of unrelated causes, except 1 with metastatic AC who died of pneumonia (Table 3B).

Histologic classification comparing bronchoscopic samples versus surgical specimens showed only 5 discordant

TABLE 2. Clinical outcome of patients with bronchial carcinoid after initial bronchoscopic treatment with or without completion surgery

\begin{tabular}{lrclccl}
\hline Histologic subtype & No. & Treatment & \multicolumn{1}{c}{ Outcome } & Alive & Dead & Remarks \\
\hline Typical & 30 & IBT & CR & 26 & 4 & All deaths unrelated \\
& 1 & IBT & Residual & 1 & & No symptoms and refused surgery \\
Atypical & 26 & CS & CR & 26 & 0 & Complete eradication at first session \\
& 3 & IBT & CR & 3 & 0 & Metastatic disease at referral \\
& 1 & IBT & Metastatic disease & 1 & 0 & Unrelated death \\
& 10 & CS & CR & 9 & 1 & Pneumonia with liver metastases \\
\hline
\end{tabular}

IBT, Initial bronchoscopic treatment; $C R$, complete response with no residual tumor detected macroscopically (videobronchoscopy, high-resolution computed tomography, and endobronchial ultrasonography since 2003) and microscopically (biopsy and brush specimens) or by histologic confirmation of surgically resected specimens, which always included systematic lymph node dissection, showing radical resection and N0 status; CS, completion surgery. 
TABLE 3A. Follow-up of patients still alive in months from initial bronchoscopic treatment until August 2006

\begin{tabular}{|c|c|c|c|c|c|}
\hline \multirow[b]{2}{*}{ Carcinoid } & \multirow[b]{2}{*}{ Treatment } & \multirow[b]{2}{*}{ Outcome } & \multicolumn{2}{|c|}{ Follow-up (mo) } & \multirow[b]{2}{*}{ Remarks } \\
\hline & & & Median & Range & \\
\hline \multirow[t]{5}{*}{ Typical } & $\operatorname{IBT}(\mathrm{n}=27)$ & $C R(n=26)$ & 92 & $14-180$ & \\
\hline & & Residue $(\mathrm{n}=1$ ) & 110 & & Refused surgery \\
\hline & $\operatorname{CS}(n=26)$ & $C R(n=25)$ & 66 & $16-172$ & \\
\hline & & Recurrence $(\mathrm{n}=1)^{*}$ & 103.5 & & Follow-up from IBT until CS \\
\hline & & & 16 & & $\begin{array}{l}\text { Follow-up from CS until } \\
\text { August } 2006\end{array}$ \\
\hline \multirow[t]{5}{*}{ Atypical } & IBT $(n=4)$ & $C R(n=3)$ & 14 & $14-74.5$ & \\
\hline & & Metastatic $(\mathrm{n}=1)$ & 27 & & Palliative BT \\
\hline & $\operatorname{CS}(\mathrm{n}=9)$ & $\mathrm{CR}(\mathrm{n}=8)$ & 51.5 & $13-86.5$ & \\
\hline & & Recurrence $(n=1)^{*} \dagger$ & 115.5 & & Follow-up from IBT until CS \\
\hline & & & 18.5 & & $\begin{array}{l}\text { Follow-up from CS until } \\
\text { August } 2006\end{array}$ \\
\hline
\end{tabular}

IBT, Initial bronchoscopic treatment; $C R$, complete response with no residual tumor detected macroscopically (videobronchoscopy, high-resolution computed tomography, and endobronchial ultrasonography since 2003) and microscopically (biopsy and brush specimens) or by radical resection judged on surgical specimens all NO with systematic nodal dissection always performed; CS, completion surgery. *Delayed completion surgery, protocol violation after fifth year, delayed detection of extraluminal tumor recurrence. † Histologic type typical carcinoid at initial bronchoscopic treatment and atypical carcinoid at completion surgery.

cases. In 2 cases, mitotic index shifted from 0 to 2 mitotic figures $/ 2 \mathrm{~mm}^{2}$, in 1 from 1 to 3 mitotic figures $/ 2 \mathrm{~mm}^{2}$, and in the last 2 from 0 to 4 mitotic figures $/ 2 \mathrm{~mm}^{2}$.

\section{Discussion}

Current understanding of tumor growth and behavior with regard to the development of local and distant disease has enabled us to consider alternative strategies that are aimed toward optimal outcome in terms of maximum preservation of quality of life. Especially in dealing with clinically less malignant tumor type and in light of increasing recognition of the long lead time that may occur, one needs to reflect and remain vigilant to enable parenchyma-sparing resection whenever feasible. ${ }^{22}$ Although from an oncologic point of view surgery should be considered the criterion standard, surgical bronchoplasty has been an accepted strategy in BC treatment. ${ }^{6,12}$ In line with this, prevention of extensive parenchymal resection is the aim of bronchoscopic treatment. ${ }^{6,12,22,23}$ We have increasingly recognized the poten- tial of a comprehensive approach in fully exploiting the advantages of minimally invasive approaches, including IBT. ${ }^{17,18,24-27}$ Diligent and careful workup and follow-up with state-of-the-art technologies are key for this new paradigm. Technical advances have also improved the ability to monitor intraluminal disease processes in the submillimeter range. ${ }^{17,18}$

According to our data, clinical bronchoscopic classification of carcinoids as intraluminal or extraluminal could become of more clinical importance than histologic classification per se. ${ }^{3}$ In this study, the former distinction was crucial in determining treatment modality. As mentioned before, the Travis classification is based on retrospective analysis of surgical data and thus lacks any information about tumor growth pattern. It is possible that all those cases represent a different cohort of neuroendocrine tumors, more likely located in the lung parenchyma. We thus may be dealing with a different patient cohort.

TABLE 3B. Follow-up (survival) of deceased patients with bronchial carcinoids

\begin{tabular}{|c|c|c|c|c|c|}
\hline Histologic type & Treatment & Outcome & Follow-up (mo) & Cause of death & Remarks \\
\hline \multirow[t]{4}{*}{ Typical } & IBT $(n=4)$ & $C R(n=4)$ & 83 & Metastatic sarcoma & \\
\hline & & & 48 & Unknown & \\
\hline & & & 114 & Cardiovascular & \\
\hline & & & 2 & Pulmonary embolism & Cardiovascular morbidity \\
\hline \multirow[t]{2}{*}{ Atypical } & $\operatorname{CS}(n=2)$ & $\mathrm{CR}(\mathrm{n}=1)$ & 65.5 & Murdered & \\
\hline & & Metastatic $(\mathrm{n}=1)$ & 47 & Pneumonia & Died with liver metastases \\
\hline
\end{tabular}

$I B T$, Initial bronchoscopic treatment; $C R$, complete response with no residual tumor detected macroscopically (videobronchoscopy, high-resolution computed tomography, and endobronchial ultrasonography since 2003) and microscopically (biopsy and brush specimens) or by radical resection judged on surgical specimens all NO with systematic nodal dissection always performed; CS, completion surgery. 


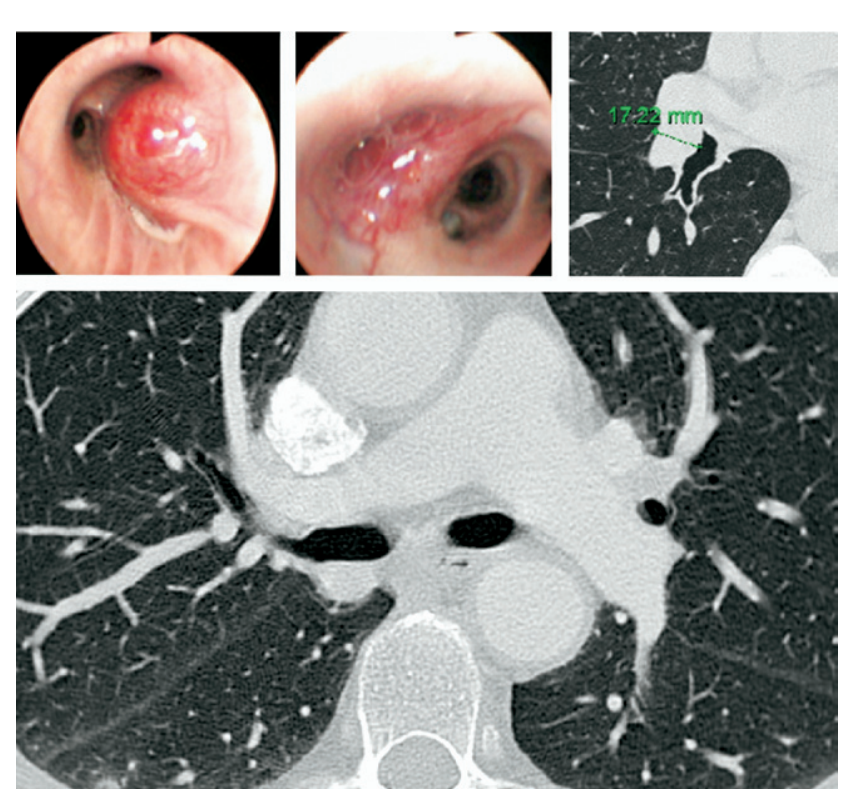

Figure 2. Examples of tumoral extent assessment with bronchoscopy and high-resolution computed tomography.

Discrepancies in histologic classification between bronchoscopic and surgical specimens collected $(n=5)$ did not have any impact on either treatment strategy or clinical outcome. All specimens showed extraluminal growth, and surgical resection was required.

Our current ability to evaluate tumors in the submillimeter range enables us to execute the optimal strategy without significant treatment delay that could affect outcome. ${ }^{17-19}$

There were only 2 cases with late detected recurrence, apparently the result of incomplete removal of submucosal disease by IBT. Despite a more than 4.5-year delay, however, the outcome would not have been different had surgery been performed earlier. Furthermore, long-term follow-up showed only 1 death attributable to metastatic $\mathrm{AC}$, indicating the low malignant potential of BC.

In practice, even if surgical resection is still considered the only accepted strategy, initial bronchoscopic tissue sampling for definite histologic typing should also be exploited to eradicate intraluminal tumor mass completely. There is then ample time for rethinking and restaging before further treatment is considered necessary.

Current analysis underscores the sophistication of noninvasive and minimally invasive techniques such as HRCT scans and bronchoscopic techniques, as shown in Figure 2. Although this is essentially discordant with our strategy, lately in some patients with AC the tumors have been completely removed at the IBT session and surgery has been postponed.

One recent study of TC treated bronchoscopically showed encouraging long-term results. ${ }^{28}$ There have, however, been no previous prospective clinical, practical, sys- tematic studies of the role of IBT in patients with intraluminal BC. One retrospective study ${ }^{2}$ mentioned data from Israel comprising $68 \%$ centrally located BCs that may resemble the cohort potentially suitable for the IBT approach. On the basis of our findings of the central registry crude data, however, only $10 \%$ of the yearly average cases in the Netherlands have been referred to us. We may therefore assume that at least approximately $5 \%$ of all $\mathrm{BC}$ can be treated solely with IBT, because referral bias by pulmonologists in The Netherlands cannot be ruled out. They may have excluded from referral all patients with known extraluminal and parenchymal BC lesions. These may represent the same cohort as studied by Travis and colleagues. ${ }^{3}$

In summary, our longitudinal data regarding the integration of IBT into the treatment of patients with $\mathrm{BC}$ in the central airway suggest a logical and feasible clinical practice that challenges all presumed objections that immediate surgical resection is absolutely required and that any delay may compromise outcome. IBT strategy is therefore an underrecognized and potentially tissue-sparing approach that does not compromise outcome. Careful judgment of intraluminal versus extraluminal tumor growth is currently feasible, allowing timely recognition of patients who require surgical resection. Our long-term data underscore the low malignant potential of BC, with only 1 disease-specific death in our population. A large number of patients remain alive, and more detailed retrospective quality of life and cost-effectiveness analyses are being performed.

\section{References}

1. Davila DG, Dunn WF, Tazelaar HD, Pairolero PC. Bronchial carcinoid tumors. Mayo Clin Proc. 1993;68:795-803.

2. Fink G, Krelbaum T, Yellin A, Bendayan D, Saute M, Glazer M, et al. Pulmonary carcinoid: presentation, diagnosis, and outcome in 142 cases in Israel and review of 640 cases from the literature. Chest. 2001;119:1647-51.

3. Travis WD, Rush W, Flieder DB, Falk R, Fleming MV, Gal AA, et al. Survival analysis of 200 pulmonary neuroendocrine tumors with clarification of criteria for atypical carcinoid and its separation from typical carcinoid. Am J Surg Pathol. 1998;228:934-44.

4. Ducrocq X, Thomas P, Massard G, Barsotti P, Giudicelli R, Fuentes P, et al. Operative risk and prognostic factors of typical bronchial carcinoid tumors. Ann Thorac Surg. 1998;65:1410-4.

5. Martini N, Zaman MB, Bains MS, Burt ME, McCormack PM, Rusch VW, et al. Treatment and prognosis in bronchial carcinoids involving regional lymph nodes. J Thorac Cardiovasc Surg. 1994;107:1-7.

6. Okike N, Bernatz PE, Woolner LB. Carcinoid tumors of the lung. Ann Thorac Surg. 1976;22:270-7.

7. Wilkins EW Jr, Grillo HC, Moncure AC, Scannell JG. Changing times in surgical management of bronchopulmonary carcinoid tumor. Ann Thorac Surg. 1984;38:339-44.

8. Cardillo G, Sera F, Di Martino M, Graziano P, Giunti R, Carbone L, et al. Bronchial carcinoid tumors: nodal status and long-term survival after resection. Ann Thorac Surg. 2004;77:1781-5.

9. Filosso PL, Rena O, Donati G, Casadio C, Ruffini E, Papalia E, et al. Bronchial carcinoid tumors: surgical management and long-term outcome. J Thorac Cardiovasc Surg. 2002;123:303-9.

10. Hage R, de la Riviere AB, Seldenrijk CA, van den Bosch JM. Update in pulmonary carcinoid tumors: a review article. Ann Surg Oncol. 2003;10:697-704. 
11. Marty-Ane CH, Costes V, Pujol JL, Alauzen M, Baldet P, Mary H. Carcinoid tumors of the lung: do atypical features require aggressive management? Ann Thorac Surg. 1995;59:78-83.

12. Stamatis G, Freitag L, Greschuchna D. Limited and radical resection for tracheal and bronchopulmonary carcinoid tumour. Report on 227 cases. Eur J Cardiothorac Surg. 1990;4:527-32.

13. Nakata M, Sawada S, Saeki H, Takashima S, Mogami H, Teramoto N, et al. Prospective study of thoracoscopic limited resection for groundglass opacity selected by computed tomography. Ann Thorac Surg. 2003;75:1601-5.

14. Endo C, Sagawa M, Sato M, Sakurada A, Aikawa H, Takahashi S, et al. What kind of hilar lung cancer can be a candidate for segmentectomy with curative intent? Retrospective clinicopathological study of completely resected roentgenographically occult bronchogenic squamous cell carcinoma. Lung Cancer. 1998;21:93-7.

15. Mathur PN, Edell E, Sutedja T, Vergnon JM. Treatment of early stage non-small cell lung cancer. Chest. 2003;123(1 Suppl):176S-80S.

16. Beasley MB, Thunnissen FB, Brambilla E, Hasleton P, Steele R, Hammar SP, et al. Pulmonary atypical carcinoid: predictors of survival in 106 cases. Hum Pathol. 2000;31:1255-65.

17. Sutedja TG, Schreurs AJ, Vanderschueren RG, Kwa B, vd Werf TS, Postmus PE. Bronchoscopic therapy in patients with intraluminal typical bronchial carcinoid. Chest. 1995;107:556-8.

18. van Boxem TJ, Venmans BJ, van Mourik JC, Postmus PE, Sutedja TG. Bronchoscopic treatment of intraluminal typical carcinoid: a pilot study. J Thorac Cardiovasc Surg. 1998;116:402-6.

19. van Boxem TJ, Golding RP, Venmans BJ, Postmus PE, Sutedja TG. High-resolution CT in patients with intraluminal typical bronchial carcinoid tumors treated with bronchoscopic therapy. Chest. 2000; 117:125-8.
20. Dumon JF, Shapshay S, Bourcereau J, Cavaliere S, Meric B, Garbi N, et al. Principles for safety in application of neodymium-YAG laser in bronchology. Chest. 1984;86:163-8.

21. Kurimoto N, Murayama M, Yoshioka S, Nishisaka T, Inai K, Dohi K. Assessment of usefulness of endobronchial ultrasonography in determination of depth of tracheobronchial tumor invasion. Chest. 1999; 115:1500-6.

22. Pasic A, Postmus PE, Sutedja TG. What is early lung cancer? A review of the literature. Lung Cancer. 2004;45:267-77.

23. Chhajed PN, Eberhardt R, Dienemann H, Azzola A, Brutsche MH, Tamm M, et al. Therapeutic bronchoscopy interventions before surgical resection of lung cancer. Ann Thorac Surg. 2006;81:1839-43.

24. Furuse K, Fukuoka M, Kato H, Horai T, Kubota K, Kodama N, et al. A prospective phase II study on photodynamic therapy with photofrin II for centrally located early-stage lung cancer. The Japan Lung Cancer Photodynamic Therapy Study Group. J Clin Oncol. 1993;11:1852-7.

25. Lederle FA. Lobectomy versus limited resection in T1 N0 lung cancer. Ann Thorac Surg. 1996;62:1249-50.

26. Onishi H, Araki T, Shirato H, Nagata Y, Hiraoka M, Gomi K, et al. Stereotactic hypofractionated high-dose irradiation for stage I nonsmall cell lung carcinoma: clinical outcomes in 245 subjects in a Japanese multiinstitutional study. Cancer. 2004;101:1623-31.

27. Yamato Y, Tsuchida M, Watanabe T, Aoki T, Koizumi N, Umezu H, et al. Early results of a prospective study of limited resection for bronchioloalveolar adenocarcinoma of the lung. Ann Thorac Surg. 2001;71:971-4

28. Luckraz H, Amer K, Thomas L, Gibbs A, Butchart EG. Long-term outcome of bronchoscopically resected endobronchial typical carcinoid tumors. J Thorac Cardiovasc Surg. 2006;132:113-5. 